\title{
A14 THE RHEUMATOID ARTHRITIS AND JUVENILE IDIOPATHIC ARTHRITIS ASSOCIATED MAJOR (A) ALLELE OF RS2104286 IS A LOSS OF EXPRESSION VARIANT OF IL2RA
}

Joanna Clark, ${ }^{1}$ Anne Hinks, ${ }^{2}$ Stephen Eyre, ${ }^{2}$ Wendy Thomson, ${ }^{2}$ Andrew Cope ${ }^{1}{ }^{1}$ Academic Department of Rheumatology, King's College School of Medicine, King's College London, London; ${ }^{2}$ Arthritis Research UK Epidemiology Research Unit, University of Manchester, UK

\subsection{6/ard.2010.149096.14}

Background and objectives The IL2RA/CD25 locus on chromosome $10 \mathrm{p} 15$ is emerging as a strong candidate susceptibility gene for the development of a range of autoimmune diseases, including rheumatoid arthritis, juvenile idiopathic arthritis, vitiligo, lupus, multiple sclerosis and type I diabetes. Variants that modify the function of the IL-2/IL-2R pathway are biologically highly plausible susceptibility variants, given recent data suggesting that IL-2 is a key cytokine involved in promoting peripheral tolerance through the generation and maintenance of regulatory $T$ cell subsets, and suppressing expression of IL-17. While a number of allelic variants of IL2RA have been identified in fine mapping studies, the functional consequences of carrying a disease associated IL2RA variant are far from clear. In this study we evaluated the expression of IL-2R $\alpha$ mRNA and protein in $\mathrm{T}$ cells from donors carrying the major and/ or minor allele of the intron $1 \mathrm{rs} 2104286$ single nucleotide polymorphism, since the major (A) allele has been shown to be associated with risk of developing rheumatoid arthritis (RA) and juvenile idiopathic arthritis (JIA).

Materials and methods Fifty healthy donors were genotyped for expression of the protective $(\mathrm{G})$ or risk $(\mathrm{A})$ alleles of rs2104286. Expression of IL-2R $\alpha$ mRNA in peripheral blood T cells was determined by RT-PCR and protein by flow cytometry, before or $4-24 \mathrm{~h}$ after stimulation with anti-CD3/CD28 beads.

Results We detected no differences in expression of IL-2R $\alpha$ protein on resting peripheral blood $T$ cells between GG, GA or AA donors. In contrast, activation induced expression of IL-2R $\alpha$ was reduced in T cells from AA and AG donors, as compared to GG donors, $24 \mathrm{~h}$ after TCR stimulation. This was associated with a decrease in the percentage of $\mathrm{CD} 25^{\text {hi }}$ but not $\mathrm{CD} 25^{\text {int }} \mathrm{T}$ cells derived from AA donors. A comparison of levels of mRNA expression in T cells from AA and GG donors after TCR stimulation revealed that donors carrying two copies of the protective $G$ allele express higher levels of IL-2R $\alpha$ mRNA than donors homozygote for the A risk allele.

Conclusions Our experiments indicate that susceptibility to JIA and RA, through carriage of the major A allele is associated with reduced expression of IL-2R $\alpha$ mRNA and protein. This, RA and JIA associated IL2RA mutants are loss of expression variants. 